\title{
Nitrogen-15 Magnetic Resonance Spectroscopy. VII. Chemical Shifts of para-Substituted Nitrobenzenes ${ }^{1}$
}

\author{
David T. Clark and John D. Roberts \\ Contribution No. 3308 from the Gates and Crellin Laboratories of Chemistry, \\ California Institute of Technology, Pasadena, California. \\ Received September 30, 1965
}

\begin{abstract}
The ${ }^{15} \mathrm{~N}$ chemical shifts of a series of para-substituted nitrobenzenes have been measured. Comparison with the para ${ }^{13} \mathrm{C}$ chemical shifts in monosubstituted benzenes and with ${ }^{19} \mathrm{~F}$ chemical shifts in para-substituted fluorobenzenes, indicates that similar factors determine the chemical shifts of these three nuclei. With $p$-nitroaniline, the ${ }^{15} \mathrm{~N}$ chemical shift appears to have an extra paramagnetic contribution, since this is the only compound studied that does not fit the correlation with ${ }^{13} \mathrm{C}$ and ${ }^{19} \mathrm{~F}$ chemical shifts.
\end{abstract}

$I^{\mathrm{n}}$ the Pople ${ }^{2}$ theory of chemical shifts, the screening constant of a nucleus $A$ is divided into four contributions

$$
\sigma_{\mathrm{A}}=\sigma_{\mathrm{AA}}^{\mathrm{d}}+\sigma_{\mathrm{AA}}^{\mathrm{P}}+\sum_{\mathrm{A} \neq \mathrm{B}} \sigma_{\mathrm{AB}}+\sigma_{\mathrm{A}, \text { ring }}
$$

where $\sigma^{\mathrm{d}}{ }_{\mathrm{AA}}$ and $\sigma^{\mathrm{p}}{ }_{\mathrm{AA}}$ are the diamagnetic and paramagnetic contributions from the electrons of atom $A, \sigma_{A B}$ is the contribution from the electrons of atom $B$, and $\sigma_{\mathrm{A}, \text { ring }}$ is the contribution due to ring currents. Investigations in this and other laboratories have shown that in the case of carbon, ${ }^{3,4}$ nitrogen, ${ }^{5-8}$ and fluorine, ${ }^{9,10}$ the main contributions to the shielding constant of the nucleus $\mathrm{A}$ comes from the paramagnetic term $\sigma^{\mathrm{P}} \mathrm{AA}$. If the comparison of shielding parameters is confined to a suitable series of closely related compounds, e.g., substituted benzene derivatives, then contributions from the substituent anisotropy $\left(\sum_{A \neq B} \sigma_{A B}\right)$ and ring current $\left(\sigma_{A, \text { ring }}\right)$ terms may be expected to remain essentially constant. If the mean electronic excitation energies, $\Delta E$, involved in the closure approximation for the $\sigma^{\mathrm{p}}{ }_{\mathrm{AA}}$ 's are also constant, then the contribution to the shielding constants from $\sigma^{\mathrm{d}}{ }_{\mathrm{AA}}$ and $\sigma^{\mathrm{p}}{ }_{\mathrm{AA}}$ may be related in a simple way to the local electron density at the nucleus. Such correlations have been reported for ${ }^{13} \mathrm{C}$ chemical shifts ${ }^{11,12}$ in monosubstituted benzenes and ${ }^{19} \mathrm{~F}$ chemical shifts ${ }^{10,12}$ in para-substituted fluorobenzenes.

By contrast there has been no detailed investigation of ${ }^{15} \mathrm{~N}$ chemical shifts in an analogous series of compounds despite the obvious theoretical interest of such an investigation. With this in mind we have examined ${ }^{15} \mathrm{~N}$ chemical shifts of a series of para-substituted ${ }^{15} \mathrm{~N}$ nitrobenzenes in the hope of demonstrating similar correlations to those found previously for the ${ }^{13} \mathrm{C}$ and ${ }^{19} \mathrm{~F}$ chemical shifts.

(1) Supported in part by the Public Health Service Research Grant 11072-02 from the Division of General Medical Sciences and the National Science Foundation.

(2) J. A. Pople, J. Chem. Phys., 37, 53 (1962).

(3) M. Karplus and J. A. Pople, ibid., 38, 2803 (1963).

(4) J. A. Pople, Mol. Phys., 7, 301 (1963).

(5) B. E. Holder and M. P. Klein, J. Chem. Phys., 23, 1956 (1955).

(6) B. M. Schmidt, L. C. Brown, and D. Williams, J. Mol, Spectry. 2, 539 (1958); ibid., 3, 30 (1959).

(7) J. B. Lambert, G. Binsch, and J. D. Roberts, Proc. Natl. Acad. Sci. U.S., 51, 735 (1964).

(8) D. H. Evans and R. E. Richards, Mol. Phys. 8, 19 (1964)

(9) M. Karplus and T. P. Das, J. Chem. Phys., 34, 1683 (1961).

(10) F. P. Prosser and L. Goodman, ibid., 38, 374 (1963).

(11) H. Spiesecke and W. G. Schneider, ibid., 35, 731 (1961).

(12) T. K. Wu and B. P. Dailey, ibid., 41, 2796 (1964).
The series of nitro compounds were chosen for study for two reasons: firstly, convenience of preparation, and secondly, because the main contribution to the paramagnetic term $\left(\sigma^{\mathrm{p}}{ }_{A A}\right)$ is expected to arise from the $\sigma \rightarrow \pi^{*}$ transitions of the nitrogen atoms. ${ }^{13}$ The energy of the latter transitions should remain roughly constant throughout the series. Also the variation in the ring current $\left(\sigma_{A, \text { ring }}\right)$ and anisotropy terms $\left(\sum_{A \neq B} \sigma_{A B}\right)$ are expected to remain constant throughout the series. (The main contribution to $\sum_{A \neq B} \sigma_{A B}$ arises from the $n \rightarrow$ $\pi^{*}$ transition of the oxygen lone pairs, and the energy of this transition is little affected by substituents in the para position, e.g., nitrobenzene $\mathrm{n}_{0} \rightarrow \pi^{*} 330 \mathrm{~m} \mu,^{14}$ $p$-nitrophenol $\mathrm{n}_{0} \rightarrow \pi^{*} 334 \mathrm{~m} \mu .{ }^{15}$ )

\section{Results and Discussion}

Table I gives the ${ }^{15} \mathrm{~N}$ chemical-shift differences of a series of para-substituted nitrobenzenes relative to ${ }^{15} \mathrm{~N}$ nitrobenzene as 15 mole $\%$ solutions in dimethyl sulfoxide. Bulk susceptibility corrections were not applied, since these are likely to be well within the experimental error $( \pm 0.16$ p.p.m.), for the relatively dilute solutions employed. The low sensitivity $\left(10^{-3}\right.$ that of ${ }^{1} \mathrm{H}$ at constant field) precludes any accurate measurement of chemical shifts over a wide range of concentrations.

The first point to note from Table $I$ is the relatively small range of chemical shifts, namely 8.23 p.p.m. This may be compared with the corresponding ${ }^{19} \mathrm{~F}$ and ${ }^{13} \mathrm{C}$ chemical shifts in para-substituted fluorobenzenes of 24.35 p.p.m. ${ }^{16 a}$ and ${ }^{13} \mathrm{C}$ chemical shifts in para-substituted toluenes of 1 p.p.m. ${ }^{16 b}$ for the same substituents. The intermediate range of the ${ }^{15} \mathrm{~N}$ chemical shifts is as expected if the paramagnetic terms $\sigma_{\text {AA }}^{\mathrm{P}}$ dominate the shielding constants for these nuclei, and is indicative that the mean electronic excitation energies are at least approximately constant in the series. ${ }^{17}$

Previous investigations have correlated the ${ }^{13} \mathrm{C}$ chemical shifts of the para-carbon atom in monosubstituted benzenes with the ${ }^{19} \mathrm{~F}$ chemical shifts of para-

(13) See ref. 3, p. 2805.

(14) K. L. Wolf and W. Herold, Z. Physik. Chem., B13, 201 (1931).

(15) K. Semba, Bull. Chem. Soc. Japan, 33, 1640 (1960).

(16) (a) R. W. Taft, E. Price, I. R. Fox, I. C. Lewis, K. K. Anderson, and G. T. Davis, J. Am. Chem. Soc., 85, 3146 (1963); (b) P. C. Lauterber, Ann. N. Y, Acad. Sci., 70, 841 (1958).

(17) A. Saika and C. P. Slichter. J. Chem. Phys., 22, 26 (1954). 


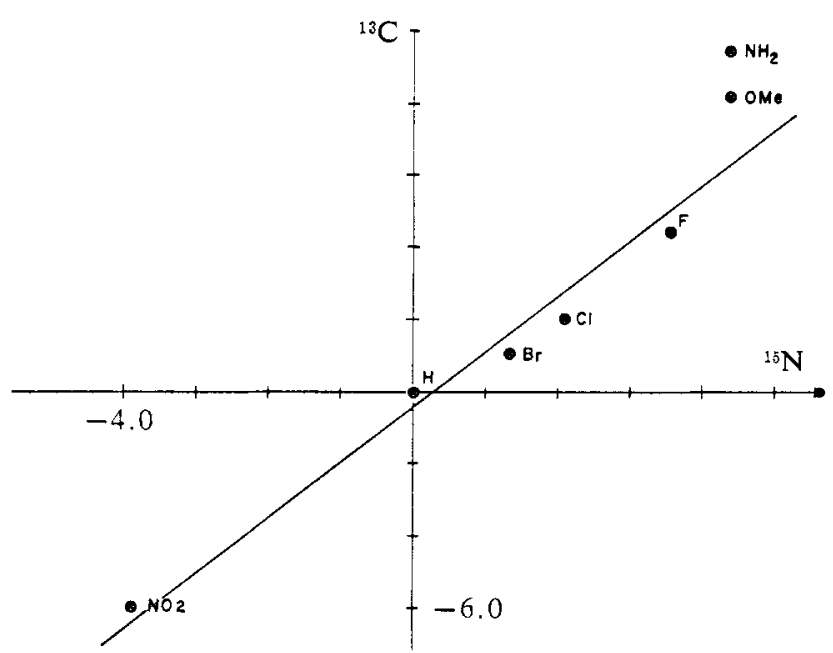

Figure 1. Plot of para- ${ }^{13} \mathrm{C}$ chemical shifts in monosubstituted benzenes $v s .{ }^{15} \mathrm{~N}$ chemical shift of nitro group in para-substituted nitrobenzenes. Data for ${ }^{13} \mathrm{C}$ are from ref. 11 .

substituted fluorobenzenes. ${ }^{12}$ In the former case, the chemical shifts are determined by the $\pi$-electron distributions at the carbon atoms, ${ }^{11}$ and the implied correlation of ${ }^{19} \mathrm{~F}$ chemical shifts with $\pi$-electron density at the attached carbon atom then arises out of the near equivalence of the terms involving the C-F $\pi$ bond order and the $\pi$-electron density on fluorine. ${ }^{10}$

Table I. ${ }^{15} \mathrm{~N}$ Chemical Shifts of the Nitro Group in para-Substituted Nitrobenzenes

\begin{tabular}{lc}
\hline Substituent & $\begin{array}{c}\text { Chemical } \\
\text { shift, } \\
\text { p.p.m. }\end{array}$ \\
\hline $\mathrm{NH}_{2}$ & 4.38 \\
$\mathrm{OMe}$ & 4.38 \\
$\mathrm{~F}$ & 3.57 \\
$\mathrm{NHCOCH}$ & 3.07 \\
$\mathrm{Cl}$ & 2.09 \\
$\mathrm{Br}$ & 1.32 \\
$\mathrm{H}$ & 0.00 \\
$\mathrm{CN}$ & -2.58 \\
$\mathrm{NO}_{2}$ & -3.85 \\
\hline
\end{tabular}

${ }^{a}$ Experimental error is approximately \pm 0.16 p.p.m. A positive value of the chemical shift indicates a shift upfield from nitrobenzene.

The ${ }^{10} \mathrm{~N}$ chemical shifts are shown plotted against the para- ${ }^{13} \mathrm{C}$ chemical shifts in monosubstituted benzenes and ${ }^{19} \mathrm{~F}$ chemical shifts in para-substituted fluorobenzenes in Figures 1 and 2. There is a good over-all correlation in the two graphs except possibly for the ${ }^{15} \mathrm{~N}$ chemical shift in $p$-nitroaniline. This would seem to confirm that similar factors are operative in determining the chemical shift of ${ }^{15} \mathrm{~N},{ }^{19} \mathrm{~F}$, and ${ }^{13} \mathrm{C}$ nuclei.

By analogy with the theory developed for the corresponding fluorine chemical shifts, ${ }^{18}$ the ${ }^{15} \mathrm{~N}$ nitro chemical shift differences in para-substituted nitrobenzenes, should depend on the following factors: (1) the $\pi$-electron density of the nitrogen atom; (2) the $\pi$-electron density at the adjacent carbon and oxygen atoms; (3) the $\mathrm{N}-\mathrm{C} \pi$ bond order; (4) the $\mathrm{N}-\mathrm{O} \pi$ bond order. The presence of the two oxygen atoms in

(18) R. W. Taft, F. Prosser, L. Goodman, and G. T. Davis, J. Chem. Phys., 38, 380 (1963).

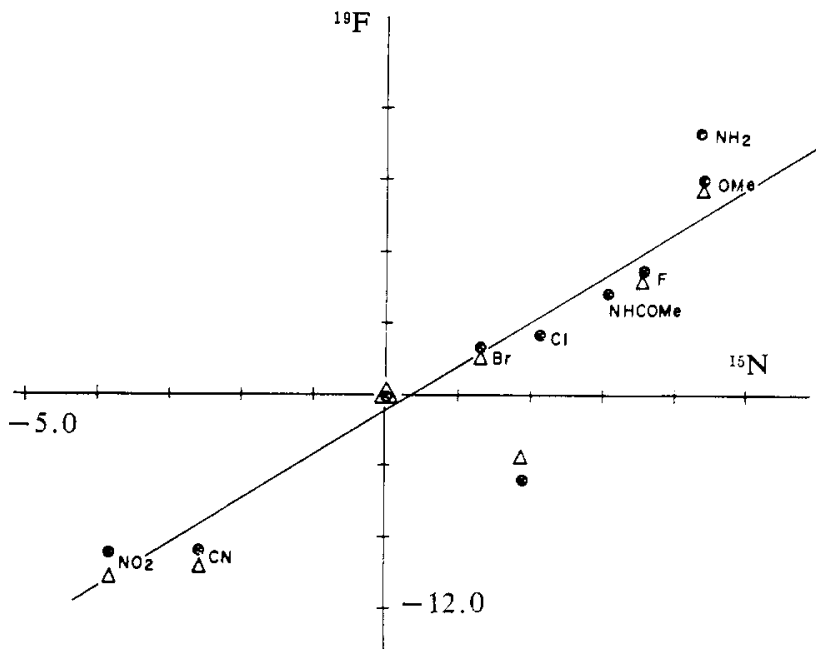

Figure 2. Plot of ${ }^{19} \mathrm{~F}$ chemical shifts in para-substituted fluorobenzenes $v s .{ }^{15} \mathrm{~N}$ chemical shift of nitro group in para-substituted nitrobenzenes: $\Delta,{ }^{19} \mathrm{~F}$ chemical shifts in dimethyl sulfoxide; $\bullet$, ${ }^{19} \mathrm{~F}$ chemical shifts in cyclohexane.

the nitro group means that the expression for the shielding parameter of the nitrogen atom will be considerably more complex than that for fluorine. However, whatever the contributing factors are, they are not all expected to operate in the same direction. ${ }^{10}$ For example, a relatively strong mesomeric substituent, such as methoxyl, should increase the electron density at the nitrogen atom (1), and also at the carbon and oxygen atoms (2), thus resulting in an upfield shift relative to nitrobenzene. The same substituent is expected to increase the $\mathrm{N}-\mathrm{C} \pi$ bond order (3), while the $\mathrm{N}-\mathrm{O} \pi$ bond order should decrease (4), the first term causing a downfield shift, the latter an upfield shift. Despite the possible subtle interplay of these factors, there is a good correlation with the corresponding ${ }^{19} \mathrm{~F}$ and ${ }^{13} \mathrm{C}$ chemical shifts, only $p$-nitroaniline is possibly anomalous. The amino group is known from spectroscopic data to have a much larger $(+M)$ effect than the other substituents, ${ }^{19}$ and this and dipole moment data ${ }^{20}$ indicate that there is considerable interaction between the amino and nitro groups. Since the increase in $\mathrm{C}-\mathrm{N} \pi$ bond order is expected to be larger than the decrease in $\mathrm{N}-\mathrm{O} \pi$ bond order, the extra paramagnetic shift implies that the former term more than compensates for the increased electron densities at the carbon, nitrogen, and oxygen atoms in p-nitroaniline. An alternative explanation would be that for $p$-nitroaniline, the charge-transfer states are much lower in energy than for the other nitrobenzenes. ${ }^{21}$ The mean electronic excitation energy $\Delta E$ for the $\sigma \rightarrow \pi^{*}$ transition might thus be expected to be smaller in this case, leading to an increased paramagnetic $\left(\sigma^{\mathrm{p}} \mathrm{AA}\right)$ contribution to the shielding constant

\section{Experimental Section}

The nitrogen-15 spectra were obtained with a Varian Model $\mathrm{V}-4300 \mathrm{~B}$ spectrometer, operated at $6.08 \mathrm{Mc}$.p.s. and 14,100 gauss,

(19) I. N. Murrell, "The Theory of the Electronic Spectra of Organic Molecules," Methuen and Co. Ltd., London, 1963, p. 226.

(20) A. L. McClellan, "Tables of Experimental Dipcle Moments," W. H. Freeman and Co., San Francisco, Calif., 1963, p. 192.

(21) Cf. ref. 20, Chapter 10 
as described previously. ${ }^{7,22}$ Most of the following compounds were prepared on a 0.5 -g. scale.

p-Nitro- ${ }^{15} \mathrm{~N}$-acetanilide was prepared by the nitration of acetanilide with $38 \%$ nitric ${ }^{15} \mathrm{~N}$ acid (Merck Sharp and Dohme $97 \%$ ${ }^{15} \mathrm{~N}$ ), according to the procedures given by Vogel. ${ }^{23}$

$p$-Nitro- ${ }^{16} \mathrm{~N}$-aniline was obtained by the acid hydrolysis of $p$ nitro- ${ }^{15} \mathrm{~N}$-acetanilide. ${ }^{23}$

Nitrobenzene- ${ }^{15} \mathbf{N}$ was prepared by the nitration of benzene with $38 \%$ nitric- ${ }^{15} \mathrm{~N}$ acid according to the method given by Vogel. ${ }^{24}$

$p$-Bromonitrobenzene-15 $\mathbf{N}$ was prepared by the nitration of bromobenzene with $38 \%$ nitric- ${ }^{15} \mathrm{~N}$ acid according to the method given by Vogel. ${ }^{25}$

$p$-Chloronitrobenzene. ${ }^{15} \mathbf{N}$ was prepared by the nitration of chlorobenzene with $38 \%$ nitric- ${ }^{15} \mathrm{~N}$ acid using similar conditions to those in the $p$-bromonitrobenzene- ${ }^{-15} \mathrm{~N}$ preparation.

(22) G. Binsch, J. B. Lambert, B. W. Roberts, and J. D. Roberts, J. Am. Chem. Soc., 86, 5564 (1964).

(23) A. I. Vogel, "A Textbook of Practical Organic Chemistry," 3rd Ed., Longmans, Green and Co., London, p. 581.

(24) Cf. ref. 23 , p. 525.
$p$-Fluoronitrobenzene- ${ }^{15} \mathbf{N}$ was prepared from fluorobenzene and $38 \%$ nitric- ${ }^{15} \mathrm{~N}$ acid in the presence of sulfuric acid at $70^{\circ}$. The product was isolated in the same way as for the nitrobenzene- ${ }^{15} \mathrm{~N}$ preparation.

$p$-Nitro-15 $\mathrm{N}$-anisole was prepared by the reaction of $p$-bromonitro${ }^{15} \mathrm{~N}$-benzene with sodium methoxide in dimethyl sulfoxide solution at room temperature. The reaction mixture was poured onto crushed ice, and the pale yellow crystals of nitro- ${ }^{15} \mathrm{~N}$-anisole were removed by filtration. The yield was almost quantitative.

$p$-Dinitro- ${ }^{16} \mathrm{~N}$-benzene (labeled with ${ }^{15} \mathrm{~N}$ in one nitrogen) was prepared by diazotized $p$-nitro- ${ }^{15} \mathrm{~N}$-aniline according to the procedure given by Hodgson, et al. ${ }^{20}$

$p$-Nitro- ${ }^{15} \mathrm{~N}$-benzonitrile was prepared from $p$-nitro- ${ }^{15} \mathrm{~N}$-aniline by the Sandmeyer reaction in a manner analogous to that previously described by Bogert and Hand. ${ }^{27}$

(25) $C f$, ref. 23, p. 527.

(26) H. H. Hodgson, F. Heyworth, and E. R. Ward, J. Chem. Soc., $1512(1948)$.

(27) M. T. Bogert and W. F. Hand, J. Am. Chem. Soc., 24, 1035 (1902).

\title{
Neighboring Carboxyl Group Participation in the Hydrolysis of Monoesters of Phthalic Acid. The Dependence of Mechanisms on Leaving Group Tendencies
}

\author{
John W. Thanassi ${ }^{1}$ and Thomas C. Bruice ${ }^{2}$ \\ Contribution from the Departments of Biological Sciences and Chemistry, \\ University of California at Santa Barbara, Santa Barbara, California. \\ Received October 9, 1965
}

\begin{abstract}
The hydrolyses of the following monohydrogen phthalate esters have been investigated in the region of the carboxyl group $\mathrm{p} K_{\mathrm{a}}^{\prime}$ : I, methyl; II, $2^{\prime}$-monochloroethyl; III, propargyl; IV, $2^{\prime}, 2^{\prime}, 2^{\prime}$-trifluoroethyl; and V, phenyl. In addition, the hydrolysis of (VI) O-phthaloyl-N-acetylserinamide was also investigated. The $\mathrm{p} K_{\mathrm{a}}^{\prime}$ values of the alcohols employed in the preparation of the esters fall in the order I $>$ II $>$ III $=$ VI $>$ IV $>$ V. Esters I and II hydrolyzed with neighboring $\mathrm{COOH}$ group participation while esters IV and V hydrolyze with $\mathrm{COO}^{-}$participation. Thus, the mechanism changes with increase in leaving tendencies. The crossover between mechanisms occurs for esters of alcohols with $\mathrm{p} K_{\mathrm{a}}{ }^{\prime}$ values of $c a .13 .5$ so that esters III and IV are equally prone to $\mathrm{COOH}$ and $\mathrm{COO}^{-}$neighboring group catalyzed hydrolysis. These results are considered in the light of the possible participation of carboxyl groups in the mechanism of esterases. Extrapolation from this study suggests that such participation could be effective but defies detection through conventional examination of $\mathrm{pH}$-rate profiles.
\end{abstract}

In order to understand the mechanism of enzyme action, it is important that the functional groups on the protein necessary for activity be identified and that their mode of action in the catalytic process be elucidated. The study of intramolecular catalysis in model systems has been a most useful tool in this direction. ${ }^{3}$ This paper deals with neighboring carboxyl group participation in the hydrolysis of half-esters of phthalic acid.

It has been demonstrated that carboxyl anion participates in the hydrolyses of acetyl salicylic acid, ${ }^{4}$ substituted phenyl acid succinates and glutarates, ${ }^{5}$ and mono-p-bromphenyl esters of substituted glutaric and succinic acids. ${ }^{6}$ On the other hand, ethyl hydrogen

(1) Postdoctoral Feliow, University of California at Santa Barbara.

(2) To whom in quiries should be addressed.

(3) T. C. Bruice, Brookhaven Symp, Biol, 15, 52 (1962).

(4) E. R. Garret, J. Am. Chem. Soc., 79, 3401 (1947).

(5) (a) H. Morawetz and E. W. Westhead, J. Polymer Sci, 16, 273 (1955); (b) E. Gaetjens and H. Morawetz, J. Am. Chem. Soc., 82, 5328 (1960). phthatate ${ }^{7}$ and methyl hydrogen 3,6-dimethylphthalate $^{8}$ hydrolyze with participation by the neighboring protonated carboxyl group. It would appear, then, that those monoesters of dicarboxylic acids having good leaving groups hydrolyze with assistance by neighboring carboxyl anion $\left(\mathrm{COO}^{-}\right)$and those having poor leaving groups hydrolyze with the aid of the neighboring carboxyl group $(\mathrm{COOH})$.

Carboxyl groups have been implicated in the mechanism of action of several enzymes. Thus, Bernhard and Gutfreund ${ }^{9}$ have found that in the ficin-catalyzed hydrolysis of benzoyl arginine ethyl ester, a carboxyl anion apparently participates in the hydrolysis of the acyl enzyme. This has been interpreted to occur by means of a rate-limiting attack of the carboxyl anion

(6) (a) T. C. Bruice and U. K. Pandit, ibid, 80, 5384 (1958); (b)

T. C. Bruice and W. C. Bradbury, ibid., 87, 4846 (1965).

(7) A. Ågren, U. Hedston, and B. Jonnson, Acta Chem. Scand., 15, 1532 (1961).

(8) L. Eberson, ibid., 18, 2015 (1964).

(9) S. A. Bernhard and H. Gutfreund, Biochem. J., 63, 61 (1956). 